BUSINESS REPORT EMERGING MARKETS - P12

THE LONG GAME ALIBABA'S 102-YEAR PLAN - P36

IDEAS AT WORK THE REALITY OF COSTS - P4O
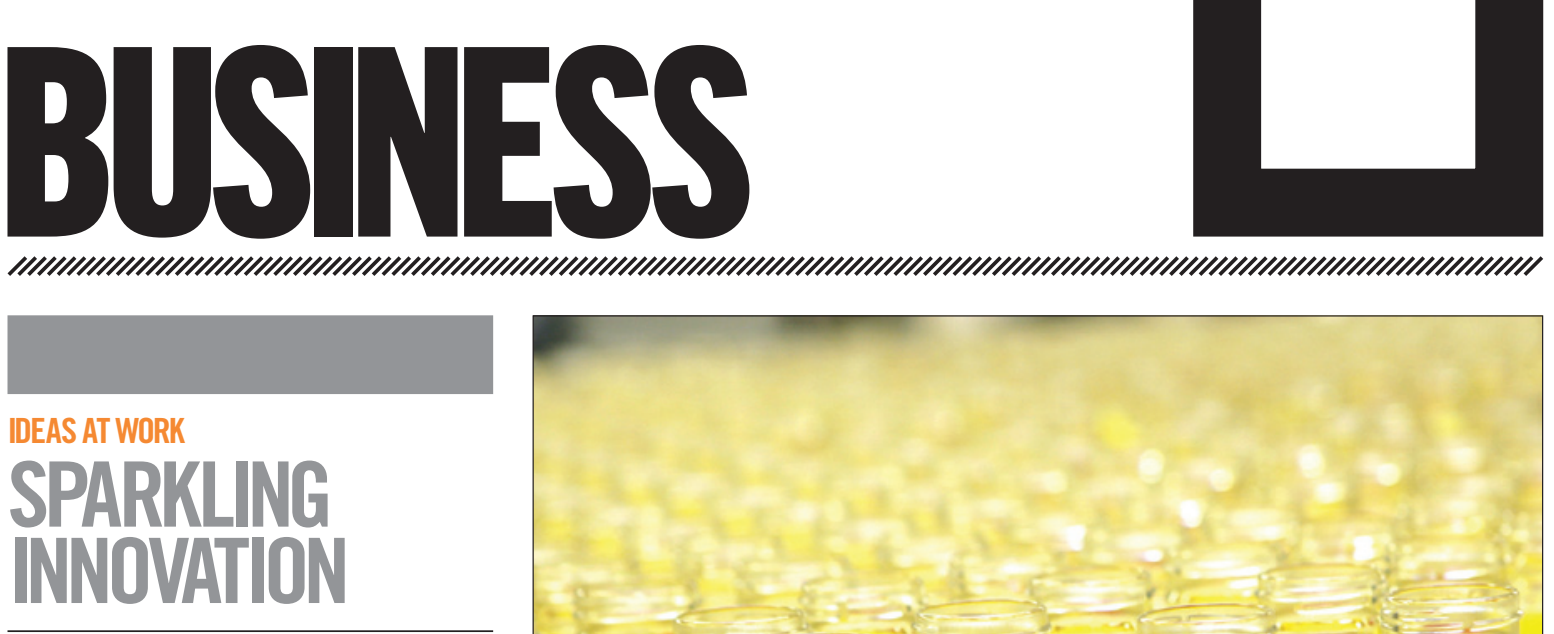

GlaxoSmithKline faced a situation common to large global organisations: how to allocate marketing resources to smaller, regional brands. Julian Birkinshaw and Peter Robbins report on the company's inventive approach to worldwide marketing that led to the development of a unique and productive network.

Focus and simplification are very much in vogue in many of the world's biggest consumer products companies. For example, Procter \& Gamble's concentration on its largest brands, largest customers and largest markets since 2000 has been a major driver of growth, and Unilever has embarked on a similar strategy of focusing on its top 50 brands.

But focus brings inevitable challenges as well. What happens to the products that don't make the cut? Do you sell them off? Do you run them as cash cows? Or do you encourage your teams to grow them without corporate support? And what about the marketing and research personnel who aren't in the focal group: do you encourage them to move on, or do you continue to look for ways to motivate and engage them? These are tricky strategic challenges, and they require thoughtful managerial responses.

GlaxoSmithKline (GSK) Consumer Healthcare is a fascinating case in point. To ensure that its

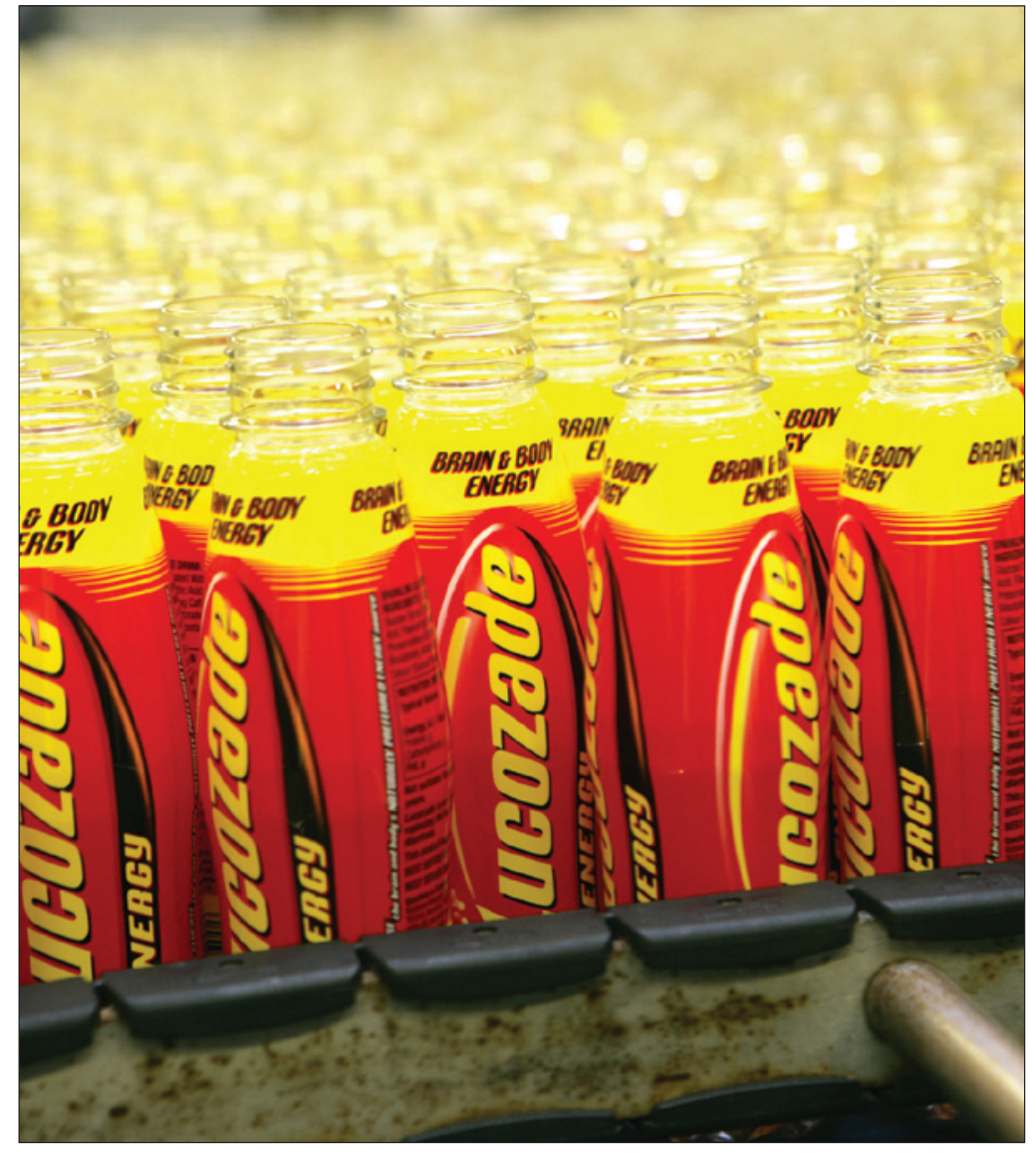

GSK: PUTTING THE FIZZ INTO REGIONAL BRANDS

lower-priority brands continued to develop, it created a community of marketing and research and development (R\&D) people around the world that came to be known as the Spark Network; it used the word 'spark' because it was intended to light up the company with new ideas and become a hotbed of creativity for the business. The network has become a valuable source of new ideas as well as a learning and support system for its members. But how do you
The Spark Network was intended to light up the company with new ideas and become a hotbed of creativity for the business. 
The company needed to strike exactly the right balance between the central creation of big brands, global plans and strategic initiatives - and local activation of those plans and programmes.

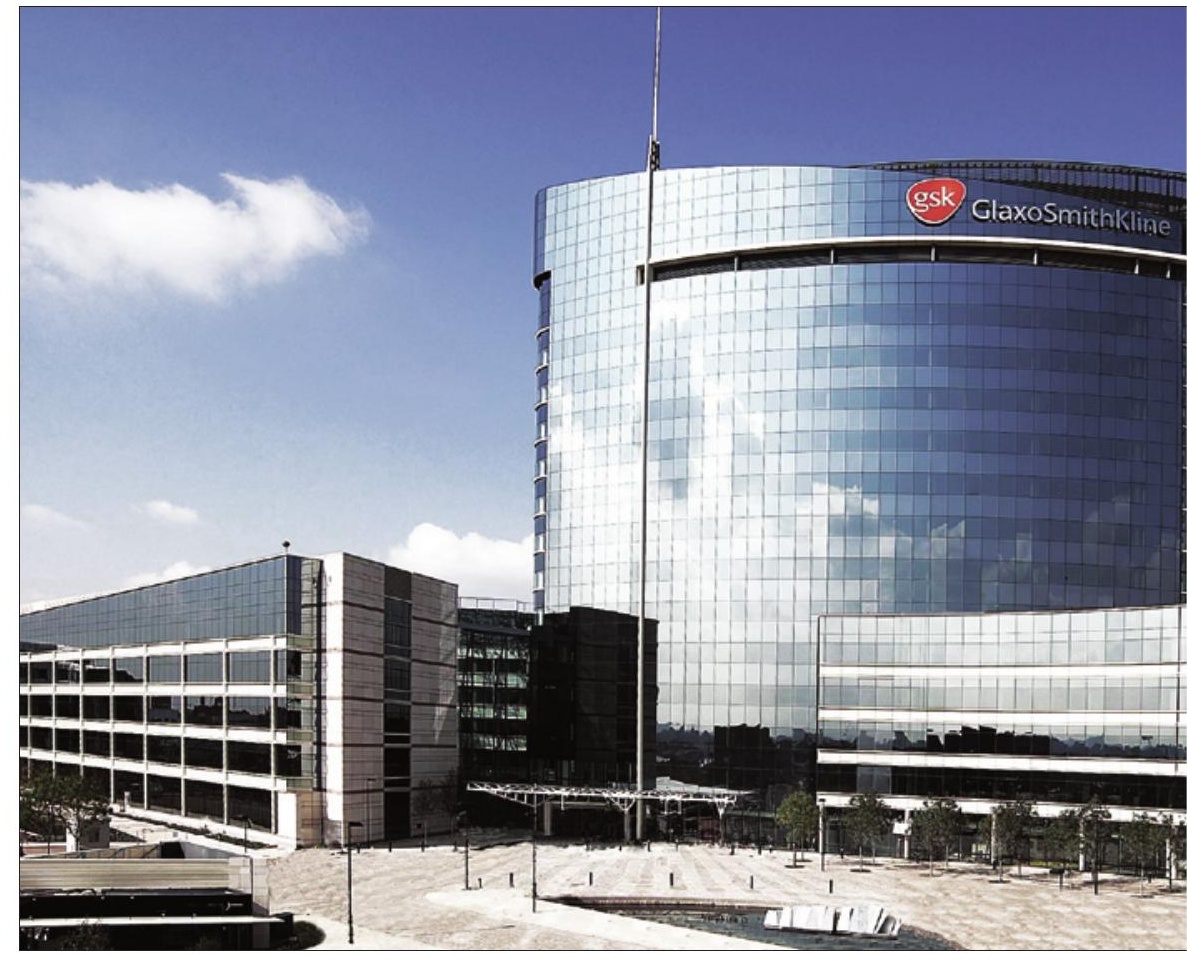

GLAXOSMITHKLINE HOUSE

a more centralised, robust and connected global marketing and R\&D organisation for our global brands - freeing-up our regional and local brands - by essentially putting decision making in the right places and at the right levels."

The Future Group was split between the UK, near London, and New Jersey in the US. People were selected from around the world to staff the group, with experts in strategy development, advertising development, new product development and $\mathrm{R} \& \mathrm{D}$. In total around 150 people across the company's top seven brands were brought together. The Future Group focused on global brand innovation and brand equity, while the individual country marketing teams retained full responsibility for local deployment. This new centralised model led to some rapid improvements, with growth up from three per cent in 2007 to $12 \%$ in 2008 .

\section{The right balance}

With the creation of the Future Group, the company needed to strike exactly the right balance between the central creation of big brands, global plans and strategic initiatives - and local activation of those plans and programmes. The role of the local marketer is very important in activation, because, naturally, the plans have no value unless they are executed with professionalism, ambition and excellence.

"With the Future Group we got a coalition of excellent, experienced and talented people working closely together and leveraging their ideas globally," said a GSK manager. "And, although the markets are centrally involved, some of them felt that they now had less of a voice in the big decisions. Most people join our marketing teams out of a sense of personal, commercial creativity, but a lot of consumer marketing in all large companies is now very mechanical, linear and logical and uses standard processes. For both these reasons, we felt a growing need for some forum by which the creativity of our people could be productively harnessed."

There were many highly successful, fast-growing brands at stake Solpadeine and Ribena in the UK and Ireland, Tums in North America, Contac in Asia, Horlicks in India. 


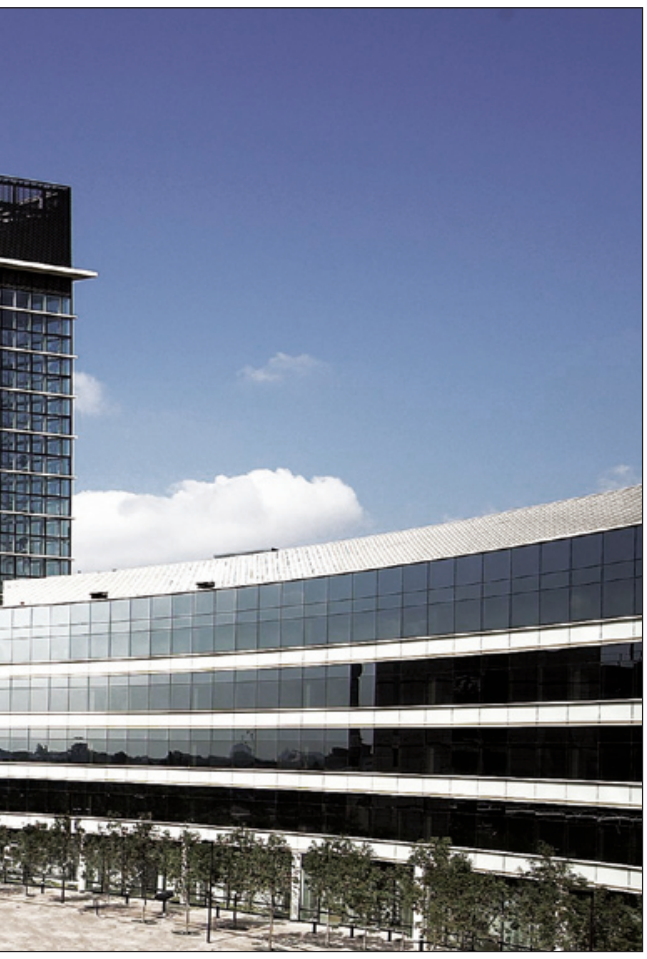

While leaders in their own markets, these brands did not have a global footprint, so it made no sense to bring them into the Future Group. But there was still a need to do something to renew and grow these brands and to keep their brand teams motivated.

\section{Igniting the spark}

John Clarke, then President of the Future Group, conceived the idea for the Spark Network and asked one of the authors (Peter Robbins) to scope it out, set it up and lead it. Unlike the members of the Future Group, who were required to move to London or New Jersey, the Spark Network was intended as a looser affiliation of people working in national markets around the world. They would continue to do their day jobs and, in addition, they would become part of this network of like-minded people. The network would provide a focal point for discussions about new product ideas, and it would provide its members with the skills they needed to achieve successful, organic innovation for their brands. The network was GSK's 'Jedi force of innovation'. Like the light-sabred heroes of Star Wars fame, the aim was to link a trained and motivated group of individuals, responsible for championing their brands and pushing an innovation agenda across the company. Clarke was looking for new ideas with scale, rather than individual pockets of single ideas.

While the model for Spark was innovative in and of itself, a number of other companies across various industries (including Mars, IBM, Bombardier, Cemex and Phillips) had established broadly comparable initiatives. How did GSK's Spark Network take shape? Regional presidents were approached to source nominees, people who were creative in their own businesses.

This brought in the marketing managers of Japan, Germany, Canada and some R\&D people. They were not volunteers as such: they were nominated as creative people and invited to join a network of like-minded people. There was a mandate from the organisation to train them as experts in innovation so that, if they already had natural leaning, they would be helped to build a very strong practitioner skill set. Fifty people were eventually attracted and a series of teleconferences began to give a sense of what was intended.

One GSK North American marketing manager put it like this: "Enterprise (local brand) marketing people don't want to get left behind, don't want to be seen as second class, just because they don't work on the global brands. The Spark Network is their way to develop their skills in innovation." The sheer size of any multinational organisation can be a barrier to innovation, especially when employees on the same business team are separated by geography and time zones. One member from Japan said, "The network is vital for connecting with other innovators in GSK; without it, we'd never know whom to approach for innovation support."

\section{Virtually together}

A tight budget meant the group couldn't afford a face-to-face meeting for the first year, so a virtual approach was taken. First came a series of introductory teleconferences and Web-enabled discussion groups so that the members of the network could start discussing their objectives, challenges and the overall agenda for local innovation in GSK Consumer Healthcare. They used software to allow people to write their ideas on a shared document while on the conference call. One discussion was about the barriers to innovation in the company; another was about developing a code of behaviour for the network with a commitment to really help one another out and to collaborate closely on innovation projects.

Next a state-of-the art website was put together specifically for the Sparkies. It incorporated the collaborative features of instant messaging, blogging, posting and tagging ideas; and it became the repository for many tools and processes adapted from the leading authors and companies in the world as proven innovation techniques. For example, when members clicked on a book cover, they received a 10-slide summary of the key concepts contained in the book. The R\&D chief in India said, "Book summaries and papers are very, very important. In my presentations, I regularly reference papers and books from the site."

The member area was searchable by company and by expertise. Behind the member photo or avatar was a detailed profile, so that likeminded individuals could connect and work on specific projects and sub-teams. The site was also home to some syndicated services, such as global market trend reports from Iconoculture, that were useful input to help Sparkies work through trends and predictions for their own business environment.

The Spark Network was also linked in to some of the global meetings organised by the Future Group. Every year, each global brand held an 'ideation' session to develop and incubate new ideas, platforms or territories by which to grow the brand. These were high-octane sessions, two and a half days at a time, with outside experts. These invitation-only sessions brought together experts, consumers and innovators in a content-rich and stimulating environment. Five Sparkies were brought along to each of these so they would learn by doing. They wouldn't normally have received an invitation in their own right, so it was a great opportunity to get involved in high-level brand development discussions. 


\section{Innovation Jam}

The group had its first full get-together, an Innovation Jam, in 2008, when 75 members of the Spark Network met in Kew Gardens, London. The CEO, John Clarke, came and was joined by innovation speakers, including Eden Project's Tim Smit. Then, for two and a half days, the Sparkies worked. They were put into teams, as if they were an innovation agency, and given a real project brief based around identifying and validating new ideas that could drive valuable growth into the company's top brands. Working through these real-life issues introduced the Sparkies to a systematic way to think about innovation. It also had a positive impact on the business, with many of the ideas subsequently incorporated into the communication programmes for their products.

The get-together obviously had an important social component as well, as it allowed the Spark Network members a chance to get to know their colleagues on a personal level. As one participant recalled, "Kew Gardens was brilliant, a real stimulus. When you have talented people from different parts of the organisation, you get enthused by what you see. It is a really highcalibre forum." Kew really connected people and made it far easier to get early-stage ideas ricocheting around the organisation with speed and purpose. It also ensured that, through working together on genuine business challenges, the group adopted a common global approach and developed a common language around innovation.

The Kew event helped to spur a series of further activities for the Spark Network. All of the Sparkies who had been to a Global Ideation event were asked to run a local or national one, for their immediate colleagues, around a key local brand. They used the Spark Network as a sounding board to help develop the ideas that emerged from their sessions. The diversity of the network, allied to the commitment of the Sparkies to innovation in GSK, meant that they made really meaningful contributions and additions to each others' ideas, making them better and stronger and giving them a higher chance of making it through the organisation.

The website's functionality was also further expanded. The group had
01 The roof of the Eden Project, Bodelva, Cornwall

02 The Botanic House at

Kew Gardens, London

03 Kew's Alpine House

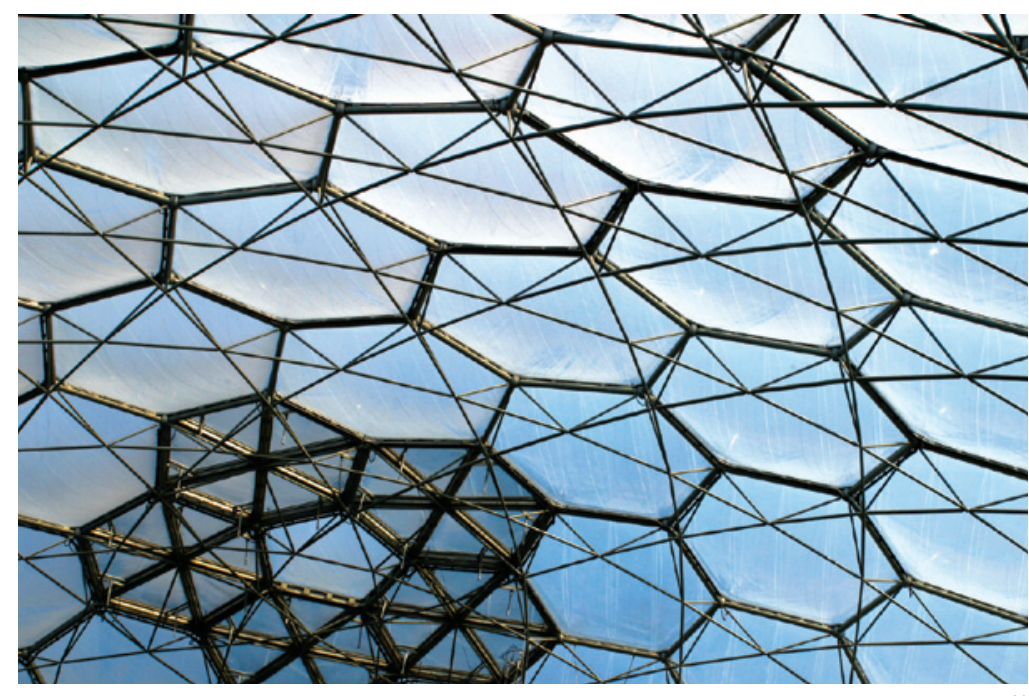

Now with 90 members, the Spark Network's value is enormous. It has given members a focal point for their own ideas, and it has helped them to meet like-minded people.

developed some good ideas; the next phase was to help members convert these raw ideas into concise concepts that really made a connection with consumers and management. To this end, they hired a specialist copywriter to run a series of modules on creative writing, since they recognised the need for a common approach to expressing marketing concepts.

The company's annual meeting, held at the corporate headquarters in May 2009, provided another opportunity to make a difference. This meeting is conventionally used to provide a total showcase of the company's innovation activities around the world. This time, the
Spark Network was able to take an active role in the event.

The Sparkies began their presentation by inputting raw, fragmentary ideas into proprietary software so they could be quickly shared. Each Sparky was asked to submit an idea during this phase. The second phase had the Sparkies site and making builds and comments upon them. The next phase was a virtual creative writing course during which members were instructed in the techniques for expressing their ideas in the most impactful way. Finally, the fourth phase drew on the 'Wisdom of Crowds' philosophy and opened the ideas (now beautifully expressed and illustrated) to the scrutiny of thousands of GSK people. A couple of GSK facilities (where the Consumer Healthcare teams are based) were allowed to come into the website to comment and vote on the ideas in order to establish which ideas would make it to a Top 50 list. Once that list was decided, the ideas were blown up and mounted on easels for display purposes.

These ideas were then displayed at the GSK Senior Leaders meeting reviewing other peoples' ideas on the 
